\title{
Editorial
}

\section{Neuroimmunology and (Epi)Genetics in Depressive Disorders}

\author{
Piotr Gałecki ${ }^{1}$ (D) Katarzyna Bliźniewska-Kowalska ${ }^{1, *(D)}$, Michael Maes ${ }^{2}$ and Kuan-Pin Su ${ }^{3, *(D)}$ \\ 1 Department of Adult Psychiatry, Medical University of Lodz, 91-229 Lodz, Poland; \\ piotr.galecki@umed.lodz.pl \\ 2 Department of Psychiatry, Faculty of Medicine, Chulalongkorn University, Bangkok 10330, Thailand; \\ dr.michaelmaes@hotmail.com \\ 3 An-Nan Hospital, China Medical University, Tainan 709, Taiwan \\ * Correspondence: katarzyna.blizniewska-kowalska@umed.lodz.pl (K.B.-K.); cobol@cmu.edu.tw (K.-P.S.)
}

check for updates

Citation: Gałecki, P.; BliźniewskaKowalska, K.; Maes, M.; Su, K.-P. Neuroimmunology and (Epi)Genetics in Depressive Disorders. J. Pers. Med. 2021, 11, 670. https://doi.org/ 10.3390/jpm11070670

Received: 7 July 2021

Accepted: 15 July 2021

Published: 16 July 2021

Publisher's Note: MDPI stays neutral with regard to jurisdictional claims in published maps and institutional affiliations.

Copyright: (c) 2021 by the authors. Licensee MDPI, Basel, Switzerland.

This article is an open access article distributed under the terms and conditions of the Creative Commons Attribution (CC BY) license (https:/ / creativecommons.org/licenses/by/ $4.0 /)$.
Depression causes individual suffering, loss of productivity, increased health care costs and high suicide risk. Despite the fact that depressive disorders are a serious brain dysfunction, their etiopathogenesis is not yet fully understood. Only $60-70 \%$ of patients suffering from Major Depressive Disorders (MDD) respond to the standard antidepressant treatment, which means that Treatment Resistant Depression (TRD) can be as prevalent as $1 / 3$ of patients with clinical depression [1]. Hence, it is essential to continue searching for possible pathological mechanisms and potential contributory factors to TRD in order to find new, effective and safe therapies.

There is strong evidence that major depression (MDD) is a neuro-immune and neurooxidative disorder with increased levels of pro-inflammatory cytokines [2,3].

Dysregulation of the immune system is recognized as one of the most important contributory factors to TRD [1]. No wonder, then, that a serious question arises: whether specific interventions such as dietary modification can influence "psychoneuroimmunity" to help fight mood disorders. Activated immune-inflammatory pathways, dysregulated hypothalam-ic-pituitary-adrenal axis (HPA axis), and psychological issues might serve as links between the pathophysiology of depression and obesity [4]. In addition, certain nutritional or nutraceutical approaches, such as omega-3 fatty acids, might improve the neuro-immune and neuro-oxidative imbalance and therefore be beneficial for depressive patients $[4,5]$.

According to the traditional monoamine theory of depression, most currently available antidepressant drugs were designed to inhibit monoamine reuptakes and increase the utilization of serotonin, noradrenaline and dopamine in the central nervous system (CNS). Now we know that monoamine deficiency is the result of more primary abnormalities. Monoamines are formed from tryptophan. However, in a situation of increased activation of the immune system, inflammatory factors cause excessive activation of IDO (indoleamine2,3-dioxygenase), an enzyme present in microglia, astrocytes and neurons, catabolizing the transformation of tryptophan into the neurotoxic kynurenine (KYN), thereby reducing the availability of tryptophan for the production of serotonin. Kynurenine, in turn, influences the intensification of neurodegenerative processes [6].

Research on twins, families and adoptive children suggests the influence of genetic factors on the development of depressive disorders. The expression of a given feature is influenced not only by the sequence of DNA nucleotides, but also by epigenetic factors [7]. The expression of a given gene can be modified by external factors such as, for example, infections, stress and diet, and then be inherited.

Due to epigenetics, new research highlights the importance of early stages of development [8], including early childhood and the prenatal period, in the etiopathogenesis of depression. According to the neurodevelopmental theory, environmental factors affecting a pregnant woman may indirectly induce epigenetic changes in the fetus, increasing its risk of developing depressive disorders. 
Regarding the biological hypotheses (e.g., neurogenic theory), several molecular factors, including those involved in neuroplasticity, might serve as biomarkers of affective disorders $[9,10]$. Some of these factors are associated with prognosis and therapeutic response. The most useful are those with a concentration that can be easily measured in the peripheral blood.

Further research into the biological basis of depressive disorders is necessary for their targeted, personalized treatment.

Funding: This research received no external funding.

Conflicts of Interest: The authors declare no conflict of interest.

\section{References}

1. Halaris, A.; Sohl, E.; Whitham, E. Treatment-Resistant Depression Revisited: A Glimmer of Hope. J. Pers. Med. 2021, 11, 155. [CrossRef] [PubMed]

2. Chi, S.; Lee, M.-S. Personalized Medicine Using Neuroimmunological Biomarkers in Depressive Disorders. J. Pers. Med. 2021, 11, 114. [CrossRef] [PubMed]

3. Gałecka, M.; Bliźniewska-Kowalska, K.; Orzechowska, A.; Szemraj, J.; Maes, M.; Berk, M.; Su, K.-P.; Gałecki, P. Inflammatory versus Anti-Inflammatory Profiles in Major Depressive Disorders-The Role of IL-17, IL-21, IL-23, IL-35 and Foxp3. J. Pers. Med. 2021, 11, 66. [CrossRef] [PubMed]

4. Patsalos, O.; Keeler, J.; Schmidt, U.; Penninx, B.; Young, A.; Himmerich, H. Diet, Obesity, and Depression: A Systematic Review. J. Pers. Med. 2021, 11, 176. [CrossRef] [PubMed]

5. Tu, C.-H.; Chen, C.-M.; Yang, C.-C.; Gałecki, P.; Su, K.-P. Brain Responses to Emotional Stimuli after Eicosapentaenoic Acid and Docosahexaenoic Acid Treatments in Major Depressive Disorder: Toward Personalized Medicine with Anti-Inflammatory Nutraceuticals. J. Pers. Med. 2020, 10, 283. [CrossRef] [PubMed]

6. Cheng, S.-W.; Li, J.-X.; Chen, D.; Chien, Y.-C.; Chang, J.; Huang, S.-Y.; Galecki, P.; Su, K.-P. Predictive Genetic Variations in the Kynurenine Pathway for Interferon- $\alpha$-Induced Depression in Patients with Hepatitis C Viral Infection. J. Pers. Med. 2021, 11, 192. [CrossRef] [PubMed]

7. Czarny, P.; Białek, K.; Ziółkowska, S.; Strycharz, J.; Barszczewska, G.; Sliwinski, T. The Importance of Epigenetics in Diagnostics and Treatment of Major Depressive Disorder. J. Pers. Med. 2021, 11, 167. [CrossRef] [PubMed]

8. Donovan, L.L.; Henningsen, K.; Kristensen, A.F.; Wiborg, O.; Nieland, J.; Lichota, J. Maternal Separation Followed by Chronic Mild Stress in Adulthood Is Associated with Concerted Epigenetic Regulation of AP-1 Complex Genes. J. Pers. Med. 2021, 11, 209. [CrossRef] [PubMed]

9. Bliźniewska-Kowalska, K.; Gałecki, P.; Szemraj, J.; Talarowska, M. Expression of Selected Genes Involved in Neurogenesis in the Etiopathogenesis of Depressive Disorders. J. Pers. Med. 2021, 11, 168. [CrossRef] [PubMed]

10. Skiba, A.; Talarowska, M.; Szemraj, J.; Gałecki, P. Is NRXN1 Gene Expression an Important Marker of Treatment of Depressive Disorders? A Pilot Study. J. Pers. Med. 2021, 11, 637. [CrossRef] 